\title{
Computing, Ethics and Social Responsibility: Developing Ethically Responsible Computer Users for the $21^{\text {st }}$ Century
}

\author{
Mildred D. Lintner \\ Department of Computer Science. Eastern Michigan University, \\ 511 Pray-Harrold Hall, Ypsilanti, Michigan 48197 USA \\ mlintner@online.emich.edu \\ http: / /www. emich.edu/compsci/faculty/f_mlintn.html
}

\begin{abstract}
Computer technology has proven itself a double-edged gift, alternately improving and threatening our lives and environment. In the past year alone we encountered computer viruses, interruptions of power, invasions of privacy, cyber-pornography, and many thefts. Our obligation to students is to include in their education the means to understand the relationship between the most powerful current influence on our lives and the ethical values necessary to use that influence responsibly. This paper outlines educational topics and methodologies for helping both beginning and pre-professional students apply ethically responsible values to using computer technology in the $21^{\text {st }}$ century.
\end{abstract}

\section{Introduction: A Double Edged Gift}

Throughout mankind's history, every powerful discovery - fire, gunpowder, medicine, nuclear power, petroleum - has proven to have two sides: Each has the potential either to improve or to threaten our lives and environments immeasurably. For each discovery, we have had to learn how to use it to best advantage to benefit mankind. We have also discovered, sometimes very painfully indeed, how easily these gifts can be misused, causing instead indescribable devastation.

In the twenty-first century, mankind has once again been entrusted with a powerful gift - computer technology. Like fire, computing has awesome beneficial powers, enabling all manner of human endeavor. It also supports devastating technological threats. Computer viruses, invasions of privacy, threats to intellectual property rights, interruptions of internet service, theft of property or identity - these and other misuses of technology fill our news media and threaten our everyday lives and activities.

Unfortunately, the technological threats we hear about or experience are the tip of an ever-growing iceberg. As we have moved into the 21 st century, computer technology has pervaded every venue of human endeavor. Computer-related technology now shapes the sociological, economical and political values of our world. As a result we can no longer afford to teach and learn only how to make computers work. We must also develop discipline from within to control use of computer technology. Our obli- 
gation to students is to provide them with the tools to harness this powerful new influence, as well as the ethical values needed to use that influence responsibly

\section{Target Audience}

Who should study the relationship between computing and ethical values? The easy answer is everyone. Computers pervade business, industry, education and personal interconnectivity. Few human activities today are performed without the intervention and/or support of computer technology. Thus, the need to understand the dangers and threats that accompany computer convenience and technology is universal.

Nevertheless, three distinct groups of students emerge as needing instruction in computing ethics: general education freshmen, pre-service teachers and computing pre-professionals.

\subsection{General Education Freshmen}

American colleges and universities require that beginning students, whatever their eventual specialization, take a series of general education courses. These are designed to insure that students meet at least minimal standards in essential subjects - written and oral communication skills, mathematics and computer fluency, among others.

First year college students exhibit a broad range of computer experiences and skilllevels. Some have had high school courses in keyboarding, beginning programming (in BASIC) or using standard productivity tools. Others are self-educated experts at interactive online games and chat rooms. Whatever computer skills these students bring with them, most approach their required general education computer course with little motivation. They feel they either know enough about computers, or can live without them. For these students, content material concerning ethical use of computers, if included at all, is usually presented in one unit at the very end of the course.

\subsection{Pre-Service Teachers}

Most United States teacher certification programs require that pre-service teachers pass state-administered qualifying examinations covering both subject content and instructional methodology. In computer science, examination areas usually include computer fluency, societal impact, programming, computer organization and architecture, professional studies and instructional technology. While few states include specific course requirements in ethical use of computing, most qualifying examinations include some questions involving ethical values. The breadth of the teaching curriculum provides many opportunities for pre-service teachers to investigate computing ethics as they relate to societal impact and computer use in schools and other public places. 


\subsection{Computing Pre-Professionals.}

Computational engineers, programmers, scientists and administrators acquire special knowledge and skills enabling them to exert great power over computer and information technology. With this power comes a variety of responsibilities, to employers, to clients, to other members of the profession, and to public safety and well-being. Thus an ethical approach to computing is an essential part of the education of a computing pre-professional.

Curricula for preparing computer professionals vary greatly, dependent on career goals and specific disciplines. While some programs do include a course in professional ethics, most do not, and provide little opportunity for adding such a course. An alternative strategy for developing ethical values in computing pre-professionals is to include ethics in many contexts and projects across the curriculum.

\section{Objectives}

Computing ethics might be taught as a single unit of a general education computer course, as one or more discrete courses in a professional curriculum, or incorporated into the content and activities of many courses across a computing discipline. Whichever academic format is used, the content and instructional methodology of a computing ethics program should guide students in attaining the following:

A Basic Foundation in Philosophical Ethics. Before students can discuss ethical concepts and evaluate computer use based on ethical concepts, they must accumulate some background knowledge in common. Minimal preparation in philosophical ethics will provide essential definitions and understandings, including the basics of several different ethical value systems that have existed throughout history.

Some Intellectual Criteria for Ethical Examination and Judgement. Students need to understand several different sets of measurements commonly used for making ethical decisions, and to be able to apply them appropriately to various technological situations.

An Understanding of Mankind's Various Uses of Double Edged Gifts. Computer technology is not the first great invention that can be used for both good and evil. Understanding earlier inventions will provide a firm base for applying ethical criteria to technological situations.

An Understanding of Everyday Ethical Issues Involving Computing. Examination of situations involving college students, young computing professionals, teenagers, parents with young children and everyday workers will help students internalize both the need for ethical values and their applications to familiar experiences.

A Responsible Attitude Toward Use of Computers and the Internet. Most students do not connect the reported horrors of Internet crime with their own uses of the Web's 
easy accessibility to ideas and products. Developing a responsible stand is especially important to pre-service teachers.

Effective Application of Critical Thinking Skills to Information and Communication Technology. Young computing professionals must be able to envision the societal impact of the products and services they will develop during their working careers.

A Code of Values Defining Personal and Commercial Uses of Computers and Related Technologies. This involves the development of random concepts concerning ethics and computer use into a consistent and cohesive guide for technology use.

Effective Communication about Abstract Ideas and Values.. This involves learning to organize ideas and support materials into a cohesive ethical stand, and to use information and communication technology appropriately to support such a stand.

\section{Content Outline}

The following content outline is suggested to support and help students attain the stated objectives. It is based on a course outline used twice so far: first with preprofessional computer programmers, and once with general education freshmen. Within the next year these offerings will be repeated, and an additional class for computer science pre-service teachers will be offered.

- Definitions of ethics and ethical use of powerful tools.

- Historical perspective

- Weapons and gun laws

- The pen and laws of libel

- The absence of a cyber-ethic

- Developing a computer ethic

- Computing and Piracy

- Issues of theft

- Ownership (of data, goods and identity)

- Intellectual property rights.

- Software piracy

- Cyber-plagiarism

- Images, sounds and multimedia

- Computing and Protection

- Security

- Passwords

- Encryption

- Identity

- firewalls

- Censorship vs. Freedom of speech

- Hate-mongering

- Pornography 
- Appropriate use

- Computing and Privacy

- Benign invasions

- Electronic supervision

- Quality control

- Vicious invasions

- Consumer Protection

- Consumer profiling

- Data mining

- Supervisory monitoring

- Secure servers

- Safe practices

- Computers and Damage Control

- Hackers and crackers

- Viruses and other dangerous invaders

- Service interruptions

- Conclusion

\section{Examples of Typical Assignments}

The study of computer ethics provides opportunity for a broad variety of assignments and projects. Here are a few examples of those used in conjunction with the outline listed above. They should, of course, be customized to both the skills level and eventual goals of the students. For all assignments, student need to prepare reports of their work. Reports can be written, using good verbal expression, or oral, using slides or other visuals, clear spoken communication and good organization.

\subsection{Ethics Scenario Evaluation}

For this assignment, the students are assigned to examine fairly detailed scenarios of computer-related situations. The scenarios can be either hypothetical or taken from real life. Several students may be assigned to the same scenario, but they seem to accomplish most if each works alone. In the first part of the assignment, each student must analyze the scenario without making any judgements, seeking specific information, such as the following: Who are the stakeholders in the situation? What are the benefits and the costs involved for each stakeholder? What actions were taken in the scenario? What alternative actions were possible?

The second part of the assignment requires the students to make decisions on ethical issues as they pertain to everyday computer tasks. Students use their own personal values as basis for all decisions. It is important for this part of the study for students to be judgmental: Was the right (or best) action taken? What would you have done if you were one of the stakeholders? Apply your own code of ethics to this scenario. Who 'won'? Who 'lost'? 


\subsection{Science Fiction Evaluation}

This assignment is best done as a group discussion project. Students read a science fiction book or short story, or see a sci-fi movie in which technology plays a major role. The technology presented does not have to be either futuristic or imaginary. Books by Jules Verne, Isaac Asimov or George Orwell or films based on their work would be appropriate.

Students begin by summarizing the story. They then list the ethical, technical and social issues addressed by the book or film. Finally they discuss the author's view of the technology used in the story - does the author consider technology good, evil, neutral, or in control? Students are then asked to compare the view of technology in their science fiction work to what they know of current technological reality - How is today's technology presented to the public? Is it good or evil? How does that compare with the author or film maker's viewpoint?

\subsection{Societal Impact Analysis}

This final example was designed specifically for computer pre-professionals. In it, students study an existing computer system or a project they have worked on and completed themselves. The system being studied should be real and functioning. The project's purpose is to understand the societal impact of the system on the population it serves.

Students analyze the working system, to determine the uses made of the system, its functional impacts on the organization and the ethical concerns of its stakeholders. Students must be able to talk to all types of stakeholders interacting with the system to determine their reactions to the workings of the system - do they consider the computer system to be a positive or negative influence on the service provided? Would using the system differently have a beneficial or destructive impact on the organization? Has the system impacted numbers or types of jobs in the organization, number or efficiency of clients served? Which stakeholders have reaped the greatest benefits (or losses) because of the system.

\section{References}

1. Hester, D. Micah, Ford, Paul J.: Computers and Ethics in the Cyberage. Prentice Hall Inc., Upper Saddle River, New Jersey (2001)

2. Johnson, Deborah G.: Computer Ethics. $3^{\text {rd }}$ edition Prentice Hall, Inc., Upper Saddle River, New Jersey (2001) 